DOI: $10.20472 / E F C .2020 .013 .006$

\author{
STEFAN ADRIANA MATEI \\ UNIVERSITATEA VALAHIA DIN TÂRGOVIȘTE, Romania \\ BRĂTĂȘANU SIMONA LUPU \\ UNIVERSITATEA VALAHIA DIN TÂRGOVIȘTE, Romania
}

\title{
INNOVATION IN ROMANIAN ENTREPRENEURSHIP
}

\begin{abstract}
:
This paper investigates the flair for business, hard work, big ideas, disruptive innovation, the intangible characteristics of an entrepreneur that determines the success of the business, by bringing in small and medium enterprises, a set of modern tools to raise the level of entrepreneurial approaches - from capitalizing on know-how and research in partnership with the business environment, to strengthen transdisciplinary entrepreneurial approaches.

Among the many qualities that help him cope with the challenges involved in developing a company, there are three essential things that every entrepreneur must possess: courage, innovation and resistance to stress.

Innovations need entrepreneurs, but the reciprocal is also valid for a successful business, it is necessary to satisfy a need that has not been satisfied so far, to offer a lower price, an innovation process is necessary.

Without the element of novelty, an entrepreneur is weak in the business world. That is why I say that innovation and entrepreneurship are two indestructibly linked fields.

Promoting entrepreneurial approaches can start to generate positive results if the vision of young entrepreneurs, the development of skills related to entrepreneurship and innovation are correlated.
\end{abstract}

\section{Keywords:}

disruptive innovation, entrepreneurship, novelty, entrepreneurial approaches.

JEL Classification: J24, A00, A10 


\section{INTRODUCTION}

The peculiarities of an entrepreneur seen as an innovator, is the basis of the paradigm according to which the entrepreneur is the individual who identifies opportunities outside the company and uses innovation as a tool of success to create a new business (Schumpeter, 1930 in Stel, Carree, Thurik, 2004, p 10). Innovation is the transformation of a new idea into a product or service that benefits both consumers and companies. Whether we are dealing with a revolutionary change or a moderate one, an innovation has as its only role the progress in one or more fields. Innovation = acceleration of time, a thought over the era in which you live.

Innovation = courage plus a little creative madness, planned sacrifice.

There are innovations that have changed humanity, such as the invention of the car or the telephone, but also others that have greatly facilitated certain processes, such as modern payment methods or car-sharing services.

Innovation and entrepreneurship disappear if they do not produce the desired effects, they are pragmatic rather than dogmatic and rather modest than grandiose - they promise to keep flexibility and the new in society, business, industry, economy or public service.

We need an entrepreneurial society where innovation and entrepreneurship are normal and continuous, becoming a life-sustaining activity in organizations, the economy and society, this can be done with the help of people who practice innovation and entrepreneurship and they make this a normal thing and a continuous phenomenon, a daily activity applied in their work within the organizations they belong to. In the context of globalization and rapid technological changes that have fundamentally changed the importance of the innovation process, small and medium entrepreneurial firms appear as a driver of innovative activity (Ács, Audretsch, 2003), being a factor of economic growth.

In continuous change, entrepreneurial behavior and innovation are dynamic and holistic processes, complementary and vital to the success and sustainability of an organization. In a dynamic external environment. In addition, organizational culture and management style are crucial factors that affect the development of entrepreneurial behavior and innovation within organizations (Zhao, 2005, p. 29).

\section{Organizational innovation and business development}

The implementation of a new method of organization in the business practices of the company, in the organization of jobs or in the external relations of the company, is called organizational innovation. Such innovation aims to increase the company's performance by reducing administrative or transaction costs, improving job satisfaction or reducing supply costs.

The ability to innovate is essential for the success of any company, if in the 1930s, the most important companies in the world had a lifespan of up to 70 years, nowadays, companies have an average age of 20 years, they are developing rapidly. thanks to innovation.

Google, Apple, Tesla, are just a few examples of relatively new companies, which have become giants thanks to innovations. Companies that do not adapt to the times and are not able to bring news to the market are simply doomed to failure.

Entrepreneurs, innovative, proactively oriented individuals who take calculated risks (Caree, Thurik, 2005, p. 8), create or develop economic activities, by identifying new opportunities, in order to generate value, depending on the temporal and spatial context in that acts.

Innovation can take many forms. Thus, we can talk about product innovation (which concerns the improvement of an old product or the development of a new one) and process innovation (which consists in replacing an old technology with a new one).

We can also talk about disruptive / incremental innovation - adding new features to existing products elements to increase efficiency through price impact and radical innovation - the 
effect of an idea materialized in an invention or unexpected model being developed on a large scale in a medium stimulant due to the lack of imitation reactions.

Figure 1 Disruptive innovation loop

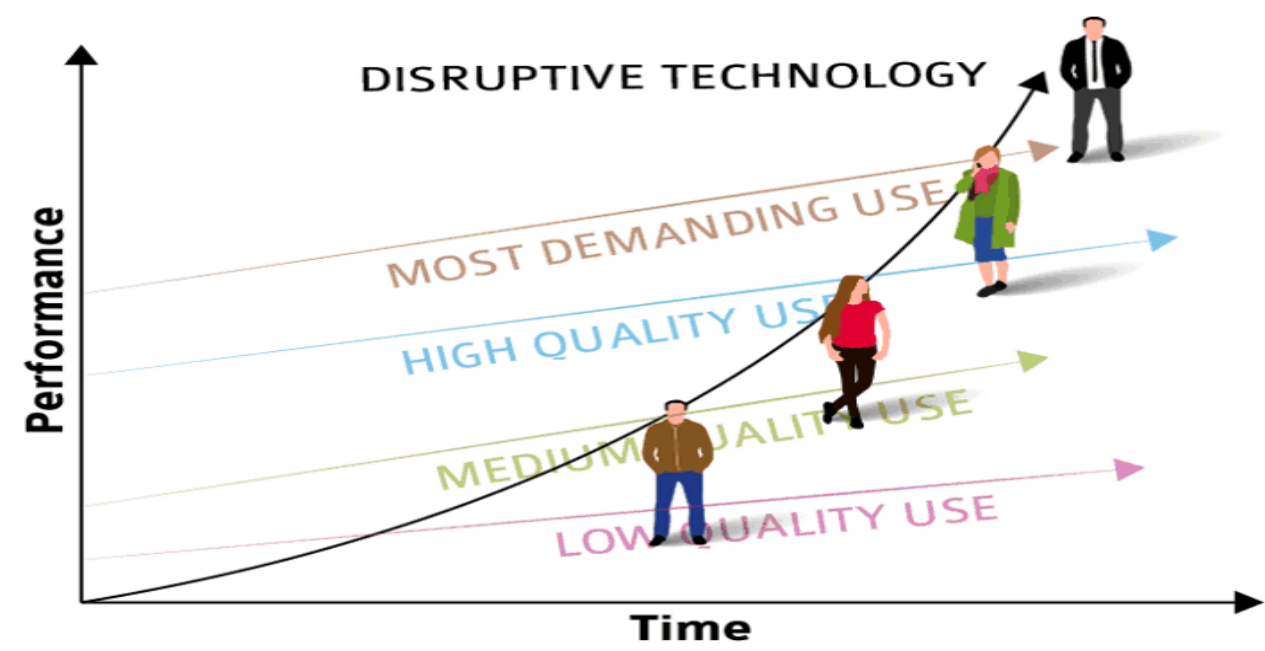

Sursa:https://medium.com/datadriveninvestor/why-uber-isnt-disruptive-but-netflix-is-disruptive-innovationexplained

Disruptive innovation, creates new markets or reconfigures new ones. It turns a product that was traditionally so inaccessible that few customers could afford it into a table product.

Young entrepreneurs with innovative ideas can test the success or failure of the business in two ways, using all market research tools to anticipate the stage at which the idea is accepted by the target audience, or experimenting with small-scale business opening to reduce costs. did not have large losses in case of failure, the application of the method, Lean Startup, the presentation of the target group, a prototype created, aimed at the reaction of potential consumers, the Internet and modern media being helpful in centralizing reactions.

If the results are not the desired ones, we must introduce the change, the adaptation of other variants, until we receive feedback from customers that what we set out to do will work in the domestic market, although this method is not a certainty.

To persuade an investor to finance an idea, an entrepreneur must have drawn up a real, well-organized plan, forecasting the current market and the future market, with evidence of viable product.

There is a pattern of innovative people with a personality that contains traits such as, an open mind, the ability to process the information they receive, arousing curiosity, creativity, knowledge based on technology, therefore most often involves people who are usually, engineers. However, startups based on an innovation that only have team engineers usually fail.

It is important that the team also includes business people, people who have experience in several fields, have experienced the transition from one industry to another, have contact with several cultures, have a developed entrepreneurial spirit, are more creative and eager to innovate.

It is important that the team also includes business people, people who have experience in several fields, have experienced the transition from one industry to another, have contact with 
several cultures, have a developed entrepreneurial spirit, are more creative and eager to innovate.

Partnerships between university / pre-university education institutions with companies, regardless of the field of activity can generate beneficial solutions, through the synergy effect. In this context can be entered the entrepreneurship contest, "ROMANIAN BUSINESS CHALLENGE", a variant of the Global Business Challenge held in New York, organized by an economic college in partnership with state organizations, associations and institutions. The competition takes place between pupils and students, in an organizational framework suitable for business development. The Chamber of Industry and Commerce - Prahova, which aims to promote companies, quality standards and their relations for business development, annually hosts the competition in Romania. The results of the competition are materialized in innovative marketing solutions, for companies that already operate, operate, and want to improve their organizational activity and efficiency in the field of activity (trade, services, marketing, industry, etc.), formulating a development strategy which ensures the mobilization of human, material and financial forces in order to achieve the objectives and goals set.

The contest organized by the co-author, Brătășanu (Lupu) Simona in Romania, in Ploiești for the first time in 2010, evolved from year to year through attractiveness and professionalism constantly provoking creativity, initiative and ability to adapt to various entrepreneurial contexts of young people, future entrepreneurs. At the eleventh edition, in which a case study of a company in the field of cosmetics and beauty products was presented, the task of students organized in multiregional teams was to find solutions to reduce risks and improve the business through marketing strategies during emergency, "COVID 19".

Within the competition, pupils and students are appreciated and evaluated by a jury composed of university professors, representatives of the Chamber of Industry and Commerce, representatives of the Guarantee Fund, small and medium enterprises, representatives of the Body of Expert Accountants and Chartered Accountants.

Figure 2 Methods used by companies to innovate

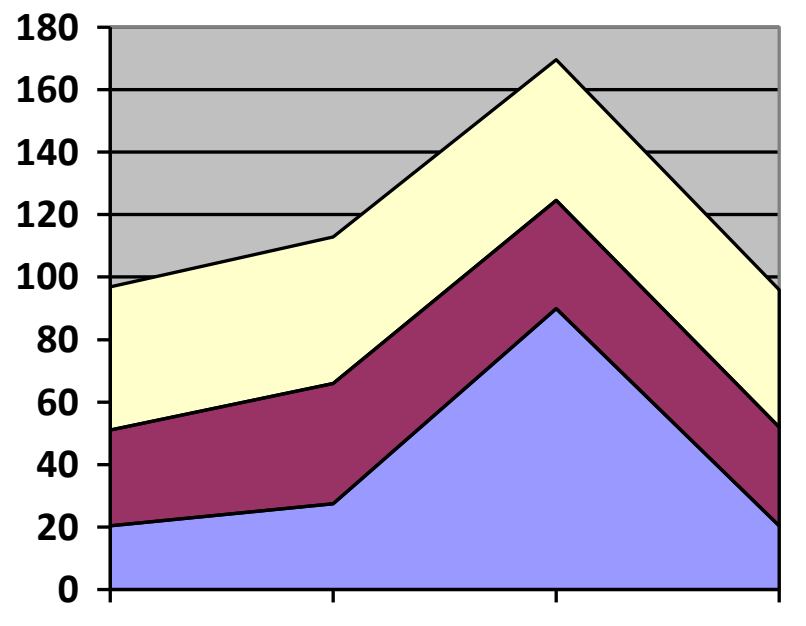

\begin{tabular}{|l|}
\hline trecerea rapida de la \\
idee la serviciu sau de \\
la prototip la produs \\
$\square$ dezvoltarea unor \\
servicii sau produse \\
noi \\
$\square$ dezvoltarea unor \\
concepte de marketing \\
perfect adaptate pietei
\end{tabular}

1st Qtr 2nd Qtr 3rd Qtr $\quad$ 4th Qtr

Source: created by the author 
Figure 3 Methods used by companies to innovate
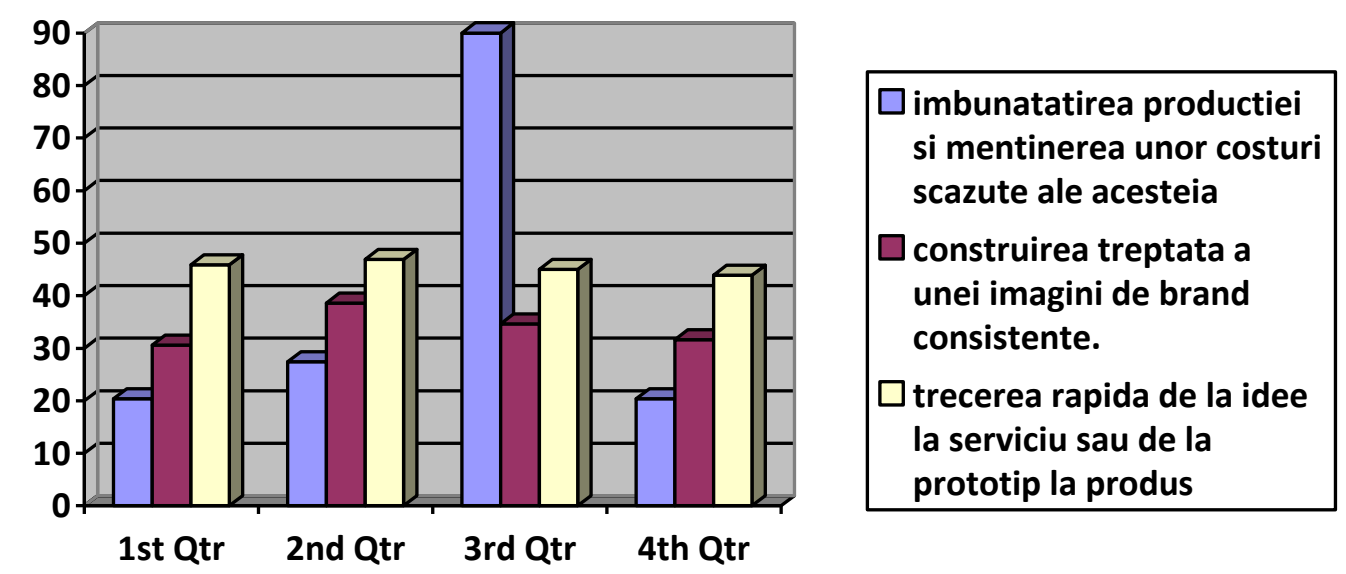

Source: created by the author

\section{The advantages of a strategy used by companies based on innovation}

The company that chooses the direction of disruptive innovation, has a much, improved productivity, low costs and good competitiveness in the market. Reconstruction of consumer products, adapted to market demand, partnerships with suppliers, informing the target audience through an entrepreneurial promotion policy, based on a written and visual communication strategy, strengthens the brand and brand name, being an advantage over the company competition.

Innovation leads to increased turnover and profit and can contribute to building an impeccable brand image, which is passed on from one generation of employees to another, if implemented correctly.

To reduce the risks when implementing an innovation, to have financial losses, innovation that consists of a new product, service, software or work procedures, which increase employee productivity, we can have the following preventive measures:

1. Advising with professional consultants, who can provide a viable point of view on the innovations that are required to be implemented in the company;

2. Association with companies from other fields that have a similar commercial vision;

3. The licensing strategy of other companies to market the created product;

4. The policy of "small steps", development in frequent stages with low costs and risks;

3. Marketing innovation.

The implementation of a new marketing method that involves significant changes in the design of the product or packaging, new methods of sale, product placement, product promotion or pricing policy involves marketing innovation. Marketing innovations aim to better meet customer needs, pursue the opening of new markets or a new positioning of the company's products on the market, with the aim of increasing sales. 
Marketing innovation refers to significant changes in the way a company sells its goods and services, including changes in design and packaging.

Many of them can be used for the first time by the company.

The main objectives of the innovative marketing are the identification and the superior satisfaction of the unmet needs of the consumers, the identification or creation of the new sales markets, the innovative positioning of the products on the market, the increase of the economic efficiency.

There are multiple directions and possibilities for achieving the innovation activity, reflected in terms of innovation marketing principles, including: anticipating consumer needs, orientation towards the end result, implementation of innovation, changing the life cycle of the product

TABLE 1: ROMANIA 'S NATIONAL INNOVATION SYSTEM

BENEFEITS

The relatively high level of public funding of the education sector;

High level of infrastructure development

Digital;

Relatively high proportion of the workforce

engaged in knowledge-intensive sectors;

Intense activity of the invention, reflected by

a very high level of national demands;

Very high number of national applications

filed for trademark and model protection

of utility;

Relatively high share of exports of goods technologically advanced and exports of creative goods;

Relatively high share of exports of services

computers and communications in total exports services.

\section{DISADVANTAGES}

School dropout, uneven quality of studies and low enrollment in university studies;

Insufficient quality (capacity) of research institutes.

Low level of physical infrastructure development;

Insufficient protection of investors' rights. Underdeveloped credit and capital market;

Small volume of private investment in research;

Excessive centralization of the national researchdevelopment system;

Underdevelopment of innovative connections;

Underfunding of technology transfers;

Too little inflow of foreign direct investment;

Low density of local companies;

Low presence of companies on the Internet;

Reduced use of information and communication technologies in business and organizations.

Opportunities

Increasing the income of the population;

The rapid expansion of Internet use in

Society;

The existence of a scientific diaspora

in important foreign research and university centers.

Deepening integration with the EU (trade, visas, FP7);

Rising food prices;

Extension of state support programs a

SMEs by introducing components

Innovation;

Donor support.

\section{Risks}

The predominance of traditionalist agricultural practices and the abandonment of the sector by young people;

Small and fragmented internal market;

The regionally polarized economy;

Emigration of labor and research staff;

Informal barriers and non - tariffs to trade;

Extensive corruption;

Defective governance model of the research and development sector. 
Source: created by the author

The purpose of the Strategy is to ensure a consistent framework of horizontal policies that will contribute to increasing the country's international competitiveness and building a knowledgebased economy, by developing human capital, by strengthening the capacities of Romanian companies to absorb, generate and disseminate innovations. by their closer interconnection with university and research centers.

\section{CONCLUSIONS}

The existence of an innovation strategy in companies is a common element of all innovation processes, the competitive advantage being the change of the existing rules for conducting business.

Breaking the rules of business is a way to promote the innovation process, but it requires, first of all, a more accurate knowledge of them, to determine which of these rules could be violated and under what conditions. innovations.

Today's innovation allows for some findings: the public encourages gadget-like

Intellectual rights are strong (so you can make money from innovation).

Corporate and multinational ethics encourage innovation.

The adoption of an innovation by some entrepreneurs does not depend on their social class, but on their attitude towards risk. Entrepreneurs can play a major role in promoting innovation.

The success of an innovation process largely depends on benefiting from the advantages generated by an element of novelty (a technological innovation, a new managerial or organizational process, etc.). Companies undertaking new actions such as: a new distribution method, a new approach in the sales process, a new manufacturing method, complete avoidance of distribution intermediaries, attracting a large part of the benefits generated by an innovation process depends on protection or not of the novelty element through documents for the protection of intellectual property rights.

To ensure success, an innovation strategy must be designed rationally, emotionally and politically.

\section{Thanks}

This paper was co-financed from the Human Capital Operational Program 2014-2020, project number POCU / 380/6/13/125245 no. 36482 / 23.05.2019 "Excellence in interdisciplinary $\mathrm{PhD}$ and post-PhD research, career alternatives through entrepreneurial initiative (EXCIA)", coordinator The Bucharest University of Economic Studies".

\section{References}

1.Ács, Z.J., Audretsch, D.B. (2003). Innovation and Technology Change, in Ács, Z.J., Audretsch, D.B., eds., Handbook of Entrepreneurship Research, Boston: Springer Publishers, pp. $55-79$

2.Bosma, N., Levie, J., Bygrave, D., Justo, R., Lepoutre, J., Terjesen, S. (2009). Global Entrepreneurship Monitor 2009 - Executive Report, Global Entrepreneurship Research Association, pp. 1-72

3.Carree, M., Thurik, R., „The Impact of Entrepreneurship on Economic Growth, Handbook of Entrepreneurship Research", International Handbook Series on Entrepreneurship, 
Vol. 1, Part 7, 2005, pp. 437-471

4.Comisia Europeană, Innovation Union Scoreboard, http://www.proinnoeurope.eu/innometrics/page/innovation-union-scoreboard-2011, 2010, 2009, 2008, 2007

5.Györfy, L.Z., Petre, S., Matiş, D., Nagy, A., Benyovski, A., Petru, T.P., „Report regarding the Entrepreneurial Activity in Romania 2008", Abel, 2008

6.Herbig, P., Golden, E.J., Dunphy, A., „The Relationship of Structure to Entrepreneurial and Innovative Success", Marketing Intelligence \& Planning, Vol. 12, No. 9, 1994,

pp. 37-48

7.Johnson, D., „What is Innovation and Entrepreneurship? Lessons for large organizations”, Industrial and Commercial Training, Vol. 33, No. 4, 2001, pp. 135-40

8.Zhao, F., „Exploring the synergy between entrepreneurship and innovation”, International Journal of Entrepreneurial Behaviour \& Research, Vol. 11, No. 1, 2005, pp. 25-41

1. Site:

https://medium.com/datadriveninvestor/why-uber-isnt-disruptive-but-netflix-is-disruptive-innovationexplained accesat la data de 3.06.2020 